\title{
EVALUATION OF IRRADIATION EMBRITTLEMENT OF A508 Gr 4N AND COMPARISON TO OTHER LOW-ALLOY STEELS
}

\author{
G. L. Wire, W.J. Beggs, and T. R. Leax
}

\begin{abstract}
This report was prepared as an account of work sponsored by an agency of the United States Government. Neither the United States Government nor any agency thereof, nor any of their employees, nor any of their contractors, subcontractors or their employees, makes any warranty, express or implied, or assumes any legal liability or responsibility for the accuracy, completeness, or any third party's use or the results of such use of any information, apparatus, product, or process disclosed, or represents that its use would not infringe privately owned rights. Reference herein to any specific commercial product, process, or service by trade name, trademark, manufacturer, or otherwise, does not necessarily constitute or imply its endorsement, recommendation, or favoring by the United States Government or any agency thereof or its contractors or subcontractors. The views and opinions of authors expressed herein do not necessarily state or reflect those of the United States Government or any agency thereof.
\end{abstract}


B-T-3450

Page 2

This page intentionally blank 
Evaluation of Irradiation Embrittlement of A508 Gr 4N and Comparison to Other Low-alloy Steels

Reference :Wire, G. L., Beggs, W. J., and Leax, T. R.

Evaluation of Irradiation Embrittlement A508 $\mathrm{Gr} 4 \mathrm{~N}$ and Comparison to Other Lowalloy steels,

Effects of Radiation on Materials, ASTM STP 1447, M. L. Grossbeck, Ed, ASTM International, West Conshohocken, PA, 2003

Abstract: $\mathrm{A} 508 \mathrm{Gr} 4 \mathrm{~N}$ has improved fracture toughness because of the addition of $3 \%$ nickel, compared to typical low alloy steels which have less than $1 \%$ nickel. However, there is an expectation in much of the recent literature, based mostly on low-alloy steels with nickel below $1 \%$, that irradiation embrittlement will increase with increasing nickel (Ni) content. In contrast, the raw irradiation test data show that ASTM A508 Grade 4N containing up to $3.7 \%$ nickel, $0.1 \% \mathrm{Cu}$ and $0.01 \% \mathrm{P}$ does not show enhanced irradiation embrittlement. A simple statistical fit to irradiation dose and irradiation temperature was developed to make direct comparisons to other low-alloy steels. Since the A508 Gr 4N data showed little discernible effect of $\mathrm{Cu}$ in the raw data, the damage may be classified as "matrix" damage. The peak irradiation embrittlement of $\mathrm{A} 508 \mathrm{Gr} 4 \mathrm{~N}$ is no greater than that of A508 Gr 2, a $0.7 \%$ Ni forging material tested under similar conditions with similar limits on $\mathrm{Cu}$ and $\mathrm{P}$. At high dose ( $80 \mathrm{mdpa}$ ) the average embrittlement of $\mathrm{A508}$ $\mathrm{Gr} 4 \mathrm{~N}$ is slightly higher (33\%) than the lower nickel materials. This trend also occurs for low copper A533B and A302B plate material. The irradiation temperature dependence of embrittlement in A508 Gr 4N is nearly the same as other low copper low-alloy steels tested over a wide range of temperatures. The increase in Charpy transition temperature in $\mathrm{A} 508 \mathrm{Gr} 4 \mathrm{~N}$ is due to radiation hardening, and the ratio of TTS to yield strength increase in $3 \mathrm{Ni}$ steels is nearly identical to that observed for conventional lowalloy steels with lower nickel.

A very detailed statistical fit was made to the overall data on $A 508 \mathrm{Gr} 4 \mathrm{~N}$ to evaluate the sensitivity of embrittlement to minor elements and to compare to results from the US surveillance test data, which is at low flux. The fit includes the effect of dose, irradiation temperature, flux, and composition. The embrittlement increased slightly at high flux, consistent with unstable matrix defects (UMD). Cu and $P$ each cause increased embrittlement in $\mathrm{A508}$ Grade $4 \mathrm{~N}$ steel, and the magnitude of the effects are similar to that for A508 Gr 2 steels irradiated in surveillance tests. Hence, it is concluded that the higher nickel A508 Grade 4N steels show nearly the same irradiation response as conventional low alloy steels with lower nickel for $\mathrm{Cu}$ levels up to about $0.11 \%$ and $\mathrm{P}$ levels up to about $0.01 \%$.

Keywords: Irradiation embrittlement, A508 Gr 4N, fracture toughness, Charpy shift, statistical modeling, copper, nickel

\section{Introduction}

The higher nickel content of $\mathrm{A508} \mathrm{Gr} 4 \mathrm{~N}$ increases the starting toughness over low alloy steels with less than $1 \%$ nickel by reducing the ductile to brittle transition temperature. Research around the world indicates that careful control of harmful species such as copper and phosphorus, etc, significantly reduces the radiation-induced embrittlement. The higher nickel low-alloy steels can provide superior toughness to conventional low alloy steels after a given irradiation dose, as long as radiation embrittlement is not more severe. Steele, Hawthorne, and Gray ${ }^{1}$ demonstrated this 
possibility over thirty years ago in irradiation tests of $3.5 \%$ nickel within the A508 Gr $4 \mathrm{~N}$ composition range, and other steels with nickel up to nearly $9 \%$. Recently, Stofanak, et al. $^{2,3}$ reported irradiation test data on a large number of heats of $\mathrm{A} 508 \mathrm{Gr} 4 \mathrm{~N}$ which also demonstrated good irradiation performance.

The improvement in fracture toughness provided by $\mathrm{A} 508 \mathrm{Gr} 4 \mathrm{~N}$ over a conventional pressure vessel steel (A508 $\mathrm{Gr} 2$ ) that has about $0.7 \% \mathrm{Ni}$ is shown in Figure 1. Here, the lower bound fracture toughness curves for many forgings of the two materials are used to characterize the starting fracture toughness curves in the absence of irradiation. The maximum Charpy transition temperatures were $100^{\circ} \mathrm{C}$ higher for $\mathrm{A508} \mathrm{Gr} 2$. The fits were performed as a function of test temperature to provide a direct comparison of properties of the two materials, avoiding the problem of indexing with Charpy transition temperatures. The $\mathrm{A} 508 \mathrm{Gr} 4 \mathrm{~N}$ steel would reach the upper shelf well below room temperature. In contrast, the $\mathrm{A508} \mathrm{Gr} 2$ material is in the transition regime until $93^{\circ} \mathrm{C}$ $\left(200^{\circ} \mathrm{F}\right)$. A508 $\mathrm{Gr} 4 \mathrm{~N}$ will preserve the advantage in fracture toughness as long as the irradiation embrittlement is similar to conventional materials.

\section{Statistical Fit of Dose and Temperature Dependence}

Irradiation test data are available on a significant number of heats of A508 Gr 4N (see Stofanak, et al..$^{2,3}$ ) and were analyzed to compare irradiation embrittlement to other materials. Superclean A508 Gr 4N steel showed much less embrittlement ${ }^{3}$, and Superclean steels were not included in this fit as they have distinctly lower levels of $\mathrm{Mn}$, $P$, and $S$. A statistical best fit of the data was developed to facilitate comparison of the effects of irradiation on this material to other materials. The fit is a simple power law in dose, with provision for the effects of irradiation temperature. Since Cu was a maximum of $0.11 \%$, and averaged only $0.07 \%$, this fit was developed without explicitly treating the effects of $\mathrm{Cu}$. Equation 1 summarizes the results from fitting the type $3 \mathrm{A508 \textrm {Gr }} 4$ data using unweighted nonlinear least squares to a model of the form

$$
\text { TTS }=\exp \left[A+B^{*} T_{i r r}+C^{*} \operatorname{Ln}(\text { dose })\right] \text { in }{ }^{\circ} \mathrm{C} \text { for conventional } A 508 \mathrm{Gr} 4 \mathrm{~N}
$$

where TTS are the Charpy transition temperate shifts, $A=4.02(3.69,4.35)$, $\mathrm{B}=-6.7 \times 10^{-3} \rho \mathrm{C}\left(-8.1 \times 10^{-3},-5.3 \times 10^{-3}\right)$ and $\mathrm{C}=0.59(0.55-0.62)$, and dose is in mapa. The numbers in parentheses are $95 \%$ confidence bounds.

One hundred and nine transition temperature shifts were used to calculate the coefficients in Equation 1. The objective of least squares analyses is to reduce the residuals to normally distributed data with constant variance, and the fit passed the normality test for the residuals. This test along with examination of the residual plots against all possible input factors was used in determining the adequacy of the fit of the model to the data. The statistical analyses were performed using the NCSS Statistical Package on a PC, and confirmed using SAS ${ }^{\mathrm{R}}$ NONLIN procedure.

The fit to the A508 Gr 4N data is shown in Figure 2, along with the upper and lower one-sided $95 \%$ prediction bounds. As indicated, the $95 \%$ prediction bounds were approximately $23^{\circ} \mathrm{C}$ above or below the mean value. This level of scatter is considered satisfactory as the fit included no allowance for variations due to chemistry or flux effects, and the intent of this fit is to compare the average embrittlement to that for other low-alloy steels. 
Separate symbols are used to denote whether $\mathrm{Cu}$ content is above or below $0.05 \%$ in Figure 2 to illustrate the point that there is very little evidence for significant effects of $\mathrm{Cu}$ on the total embrittlement. This might be expected since the maximum $\mathrm{Cu}$ was $0.11 \%$ and the average level was $0.07 \%$. Irradiation damage has been divided into a "matrix" component and a "copper rich precipitate component" in recent models of relatively large sets of data by Williams and Ellis ${ }^{4}$, and Eason, Wright, and Odette ${ }^{5}$. Williams and Ellis ${ }^{4}$ noted that many previous references support this division. For high copper steels, the $\mathrm{Cu}$ effects can be dominant ${ }^{4,5}$. As will be discussed later below, Cu effects in the A508 Gr 4N data can be detected via statistical analysis, but these effects are not large compared to the total embrittlement so that the fit in Eqn. 1 is suitable for comparison to embrittlement of other low copper steels.

\section{Comparison of A508 Gr 4N Irradiation Response to Other Low-alloy Steels}

\section{A508 Gr 4 Irradiation Embrittlement Compared to A508 Gr 2}

The radiation-induced embrittlement of $A 508 \mathrm{Gr} 4 \mathrm{~N}$ can be directly related to conventional low-alloy steels by a comparison to the $A 508 \mathrm{Gr} 2$, a conventional reactor pressure vessel material used in many commercial reactors. Irradiation embrittlement data for a series of $\mathrm{A} 508 \mathrm{Gr} 2$ steels (Cu $\leq 0.12 \%$ ) are available at similar irradiation temperature conditions to those reported by Stofanak, et al. for A508 Gr 4N. The transition temperature shifts induced by irradiation are shown in Figure 3. Type III A508 Gr 4N and A508 Gr 2 data appear very similar and largely overlap on this plot.

The upper $95 \%$ bound developed from A508 $\mathrm{Gr} 4 \mathrm{~N}$ data appears to serve as reasonable upper bound for A508 Gr 2 data. However, a significant portion of the A508 $\mathrm{Gr} 2$ data lie below the lowest A508 Gr 4N data at high dose, and the average embrittlement for $\mathrm{A} 508 \mathrm{Gr} 4 \mathrm{~N}$ is slightly larger (33\%) at high dose (80 mdpa) as shown in Figure 3. This difference is within the uncertainty in the statistical fit in Eqn 1, and may not represent a real difference. If the greater average embrittlement at high dose in A508 $\mathrm{Gr} 4 \mathrm{~N}$ is attributed to the higher level of nickel in A508 Gr $4 \mathrm{~N}$ than A508 Gr 2 (3\% vs. $0.7 \%)$, it appears that nickel has a relatively mild effect on embrittlement $(\approx 33 \%)$ at high dose.

\section{A508 Gr 4N Irradiation Embrittlement Compared to A533B and A302B Plate}

The data by Williams, et al. ${ }^{6}$ provide another opportunity to make a direct comparison on other low copper materials with irradiation test results from the same irradiation temperature range. Williams, et al. irradiated a number of A533B plate materials at $250^{\circ} \mathrm{C}$. Data are also available on $\mathrm{A} 302 \mathrm{~B}$ from testing at this laboratory. As can be seen in Figure 4, the embrittlement of low Cu plate steels is similar to A508 Gr2 with low copper, but is lower than $\mathrm{A} 508 \mathrm{Gr} 4 \mathrm{~N}$ at high dose. This trend is similar to that observed for A508 Gr 2.

\section{A508 Gr 4 N Irradiation Embrittlement Compared to Literature Data on Steels with} About 3\% Nickel

Irradiation data from testing by the Naval Research Laboratory ${ }^{7-18}$ (NRL) were compiled to compare the effects of irradiation over a wider range of material compositions and experiments. The major alloying elements of $\mathrm{HY} 80,3.5 \mathrm{NiCrMo}$, and A543 materials studied at the NRL are close to or within the range of the A508 $\mathrm{Gr} 4 \mathrm{~N}$. 
Irradiation was conducted over wide temperature ranges, but only data with specific composition including $\mathrm{Cu}$ level reported and irradiation temperatures within the range of $254-288^{\circ} \mathrm{C}\left(450-550^{\circ} \mathrm{F}\right)$ were utilized for the comparison in Figure 5. The comparison was made at an irradiation temperature of $260^{\circ} \mathrm{C}\left(500^{\circ} \mathrm{F}\right)$. This temperature is midway between $288^{\circ} \mathrm{C}\left(550^{\circ} \mathrm{F}\right)$ reported for much of the NRL literature data used in the Figure and the $232^{\circ} \mathrm{C}\left(450^{\circ} \mathrm{F}\right)$ for most of the irradiation test data on $\mathrm{A508} \mathrm{Gr} 4 \mathrm{~N}$ reported by Stofanak, et al..$^{2,3}$ Since irradiation doses were reported in $\mathrm{n} / \mathrm{cm}^{2}, \mathrm{E}>1 \mathrm{MeV}$, the exposures for A508 $\mathrm{Gr} 4 \mathrm{~N}$ were plotted in these units for this comparison. As can be seen in Figure 5, the NRL data are almost all bounded by the upper $95 \%$ A508 Gr 4 curve. In fact, the two data points that exceed the curve are from steels with large composition differences from the $\mathrm{A} 508 \mathrm{Gr} 4 \mathrm{~N}$ data ${ }^{2,3}$. The highest embrittlement observed occurred for a high $P$ heat ( $P=0.016 \%$ compared to a typical level of $0.007 \%$ ) and a high $\mathrm{Mn}$ heat ( $\mathrm{Mn}=0.79 \%$ compared to a typical level of $0.3 \%$ ). Two data points from steels with $0.2 \% \mathrm{Cu}$, the highest levels reported, are also bounded by the curve. Similar to data on superclean A508 Gr 4N, reported by Stofanak, et al. ${ }^{3}$, low embrittlement was reported for specially made materials with low $\mathrm{Cu}$ and other residuals (diamonds) and low $\mathrm{Cu}$, low $\mathrm{P}$ forgings made for improved resistance to thermal embrittlement due to phosphorus segregation (cross).

\section{Irradiation Temperature Effect on Embrittlement}

The irradiation temperature dependence for the NRL base metals is nearly identical to that derived from statistical analysis of $A 508 \mathrm{Gr} 4 \mathrm{~N}$ data, as shown in Figure 6 . The data in the Figure are from two steels that were irradiated at multiple irradiation temperatures. Tests at a temperature above $371^{\circ} \mathrm{C}\left(700^{\circ} \mathrm{F}\right)$ were not plotted because segregationinduced embrittlement can occur in a short time at high temperature ${ }^{9}$. The temperature dependence in Eqn 1 for A508 Gr 4N steels matches the directly observed temperature dependence of the $3 \% \mathrm{Ni}$ steels very well.

Jones and Williams ${ }^{19}$ recently developed a detailed correlation of irradiation temperature dependence including both base metal and welds. This correlation is plotted in Figure 6 (right axis), and it is consistent with the fit for A508 Gr 4N. Their result represents performance of low copper steels. This indicates that the irradiation temperature dependence of A508 Gr $4 \mathrm{~N}$ is very similar to that of conventional low-alloy steels at low copper levels.

\section{Irradiation Hardening and Transition Temperature Shifts}

The primary mechanism for irradiation embrittlement of low copper A508 Gr 4N was shown to be irradiation hardening since irradiation did not induce an increase in intergranular fracture. ${ }^{3}$ The hardening or increase in flow stress $\Delta \sigma$ increases the test temperature at which the flow stress is equal to the critical fracture stress. Odette ${ }^{20}$ observed that the yield strength increase and Charpy transition temperature increase were related as $\Delta T=0.5 \Delta \sigma$ for conventional plate materials, in ${ }^{\circ} \mathrm{C}$ and $\mathrm{MPa}\left(6.2^{\circ} \mathrm{F} / \mathrm{ksi}\right)$.

Data were collected from literature papers on HY80 and other high nickel steels ${ }^{13,14,21}$ to define the relationship for higher nickel steels. The higher nickel steels show the same value, $0.5^{\circ} \mathrm{C} / \mathrm{MPa}\left(5.9^{\circ} \mathrm{F} / \mathrm{ksi}\right)$. Hence, the results from $\mathrm{A} 508 \mathrm{Gr} 4 \mathrm{~N}$ and other high nickel steels are essentially the same as that for conventional RPV materials. 
Assessment of Minor Element Effects and Comparison to Conventional Low-alloy steels

Modeling of Surveillance Data by Eason, Wright, and Odette

A detailed model has been developed recently by Eason, Wright and Odette ${ }^{5}$ (EWO) to correlate the Charpy transition temperature shifts from the US Power Reactor

Embrittlement Database (PR-EDB). .The surveillance database includes over 600 test results for A302 B and A533B plate steels, A508 Gr2 and Gr 3 forging steels, and their weldments. The Cu levels extend from 0.01 to $0.41 \%$, the Ni levels are in the range $0.044-1.26 \%$, and the phosphorus levels cover $0.003-0.024 \%$. The correlation includes fluence, copper and nickel content, product form, phosphorus content, coolant temperature, and neutron flux. The model is consistent with basic understanding in that it divides the damage into contributions from "copper-rich-precipitates (CRP), phosphide precipitates (PP) and stable matrix defects (SMD)". The authors note that the "PP and the SMD terms were lumped together with other features that are independent of the CRP term." The authors also point out that "the statistical modeling of embrittlement data trends based on the concept of independent CRP and SMD contributions has been successfully used for some time by a number of workers, beginning in the mid-1980's." Starting with this basic separation into two damage components, EWO utilized advanced statistical techniques, including pattern recognition and transformation analysis to determine best-fit parameters. The correlation is an improvement over the model in Regulatory Guide 1.99 Revision 2, and achieves a significant reduction in scatter for weld and base metal subsets as well as the combined data set. The correlation was independently checked to confirm the separate terms and the $\mathrm{Cu}$ threshold.

It is of interest to examine for possible minor element effects on the embrittlement of A508 Gr $4 \mathrm{~N}$. The effects of copper are not large in the A508 Gr $4 \mathrm{~N}$ database compared to data scatter as shown in Figure 2. This is because of the relatively low copper (maximum $0.11 \%$ ) in A508 $\mathrm{Gr} 4 \mathrm{~N}$ compared to a maximum of $0.41 \%$ in the PR-EDB, and the much greater contribution of "matrix" damage at the relatively low irradiation temperature of $232^{\circ} \mathrm{C}$ employed for $A 508 \mathrm{Gr} 4 \mathrm{~N}$, compared to $288^{\circ} \mathrm{C}$ for the PR-EDB. Phosphorus and other potential embrittling agents are also restricted in the $A 5084 \mathrm{~N}$ database- $P_{\max }=0.011 \%$ for $A 508 \mathrm{Gr} 4 \mathrm{~N}$ vs $\mathrm{P}_{\max }=0.024 \%$ in the PR-EDB. It was not generally possible to detect any significant effect of minor elements on embrittlement of A508 $\mathrm{Gr} 4 \mathrm{~N}$ by direct data plotting. In order to assess whether minor elements had a discernible effect, detailed statistical analysis was necessary, as described below.

\section{Model Development for A508 Gr $4 N$}

The model developed to describe irradiation effects on $A 508 \mathrm{Gr} 4 \mathrm{~N}$ is given by:

$$
\pi \mathrm{T}=\mathrm{A} \cdot(\phi \mathrm{t}) \cdot(\phi)^{0.6595}+\mathrm{B} \cdot(\phi \mathrm{t})^{0.5858}
$$

where: TTS is the transition temperature shift due to irradiation $\left({ }^{\circ} \mathrm{C}\right)$

$\Phi t$ is the dose (mdpa)

$\Phi$ is the flux $\left(10^{-9} \mathrm{dpa} / \mathrm{s}\right)$

$\mathrm{A}=\exp \left(-7.014-4.117 \times 10^{-3} \mathrm{~T}_{\mathrm{irr}}-16.19 \mathrm{C}+4.148 \mathrm{Cr}-1.059 \times 10^{-2} \mathrm{TT}_{47 \mathrm{Ju}}-2.109 \times 10^{-4} \Phi . \Phi \mathrm{t}\right)$

$\mathrm{B}=\exp \left(1.47-4.117 \times 10^{-3} \mathrm{~T}_{\text {irr }}+81.12 \mathrm{P}+7.352 \mathrm{Cu}+3.085 \mathrm{C}\right)$

$\mathrm{T}_{\text {Irr }}$ is the irradiation temperature $\left({ }^{\circ} \mathrm{C}\right)$

$\mathrm{C}, \mathrm{Cr}, \mathrm{Cu}, \mathrm{P}$ are the concentrations of $\mathrm{C}, \mathrm{Cr}, \mathrm{Cu}$, and $\mathrm{P}(\mathrm{wt} \%)$ 
$\mathrm{TT}_{4 \mathrm{~J}, \mathrm{u}}$ is the unembrittled transition temperature $\left({ }^{\circ} \mathrm{C}\right)$ at $47 \mathrm{~J}(35 \mathrm{ft}-\mathrm{b})$

As shown in Figure 7, this model provides a very good fit to the data (standard deviation of $\left.10.0^{\circ} \mathrm{C}\left(18.1^{\circ} \mathrm{F}\right)\right)$.

The first term in the model, hereinafter referred to as the interaction term, is negligible at low flux, but is significant under high flux, high dose conditions. The second term, hereinafter referred to as the dose term, is very sensitive to the composition. A plot showing the predicted transition temperature shift at high and low flux is provided in Figure 8. The dose term is the same at both high and low flux and the interaction term is essentially zero at low flux and so is not shown separately in the plot. In this plot, the irradiation temperature was $232^{\circ} \mathrm{C}\left(450^{\circ} \mathrm{F}\right)$, the unirradiated $\mathrm{TTS}_{47 \mathrm{Ju}}$ value was set to $-62^{\circ} \mathrm{C}\left(-80^{\circ} \mathrm{F}\right)$, the level of $\mathrm{Cu}$ was $0.1 \%$, the level of $P$ was $0.01 \%$, the concentration of $\mathrm{Cr}$ was $1.75 \%$, and the concentration of $\mathrm{C}$ was set at the mean of the database $(0.18 \%)$. As shown in the plot, high flux conditions result in slightly more embrittlement than low flux conditions. This flux effect has been reported in the literature and has been attributed to vacancy related defects that form under high flux conditions ${ }^{22}$.

\section{Effect of Independent Variables on Transition Temperature Shifts}

Given the relatively large number of independent variables that affect the transition temperature shift (Equation 2), it is of interest to illustrate, on a two dimensional plot, the relative effect of each of these variables on the magnitude of the shift. One way to do this is described by Eason, Wright, and Odette ${ }^{5}$. In this method, the TTS data are normalized to median values of the independent variables:

$$
T T S_{\text {norm }}=T T S_{\text {data }}+\left(T T S_{\text {median }}-T T S_{\text {model }}\right)
$$

where: TTS $_{\text {norm }}$ the normalized value of TTS

TTS $_{\text {data }}$ the actual (measured) value of TTS

TTS $_{\text {median }}$ the model (predicted) value of TTS at the measured value of the independent variable of interest and at the median values of the other independent variables

TTS $_{\text {model }}$ the model (predicted) value of TTS at the measured values of all the independent variables

The median values of the independent variables are given in the table below.

Table 1. Median Values for Fit in Equation 2

\begin{tabular}{|c|c|}
\hline Variable & Median Value \\
\hline Fluence & $8.85 \mathrm{mdpa}$ \\
\hline Flux & $4.24 \times 10^{-8} \mathrm{dpa} / \mathrm{s}$ \\
\hline $\mathrm{T}_{\mathrm{Irr}}$ & $231^{\circ} \mathrm{C}$ \\
\hline $\mathrm{TT}_{47 \mathrm{u}}$ & $-109^{\circ} \mathrm{C}\left(-164^{\circ} \mathrm{F}\right)$ \\
\hline $\mathrm{Cu}$ & $0.07 \mathrm{wt} \%$ \\
\hline $\mathrm{P}$ & $0.007 \mathrm{wt} \%$ \\
\hline $\mathrm{C}$ & $0.19 \mathrm{wt} \%$ \\
\hline $\mathrm{Cr}$ & $1.76 \mathrm{wt} \%$ \\
\hline
\end{tabular}


Plots of the normalized transition temperature shifts as a function of selected independent variables are shown in Figures 9-12. It is important to note that the plots apply only when all but the variable of interest are at their median values. Consequently, while these plots are useful in qualitatively assessing the effects of the independent variables, any effort to quantitatively isolate the effect of any single independent variable is not justified due to the complex interactions between the variables. Best-fit curves and $95 \%$ prediction limits are provided in each of the figures. The relative effect of each of the independent variables is related to the slope of the best-fit curve. Dose has, by far, the largest effect, followed by irradiation temperature (not shown), phosphorus concentration, and copper concentration.

It is of interest to compare the sensitivity of embrittlement due to $\mathrm{P}$ and $\mathrm{Cu}$ for $\mathrm{A508 \textrm {Gr }}$ $4 \mathrm{~N}$ to that observed for conventional low-alloy steels as determined by EWO. This cannot be done on a direct basis for $\mathrm{P}$, because of the lumping of PP and SMD terms in EWO. Also, the central temperature of the PR-EDB is $288^{\circ} \mathrm{C}$, where "matrix" damage is much lower than at median value of $231^{\circ} \mathrm{C}$ for $\mathrm{A508} \mathrm{Gr} 4 \mathrm{~N}$. The EWO formulation is stated to be valid to $260^{\circ} \mathrm{C}^{5}$ and at this temperature the formulation would project a $12^{\circ} \mathrm{C}$ increase in embrittlement for the $P$ change indicated in Figure 11, reasonably similar to that indicated for $\mathrm{A} 508 \mathrm{Gr} 4 \mathrm{~N}$.

There is no evidence for a threshold level for the onset of increased embrittlement due to $\mathrm{Cu}$ in $\mathrm{A} 508 \mathrm{Gr} 4 \mathrm{~N}$ in Figure 10, in contrast to the $0.072 \%$ threshold reported by EWO for conventional low-alloy steels. However, the effect of copper is considered to be substantially independent of temperature in the literature ${ }^{4,5}$. The embrittlement associated with $\mathrm{Cu}$ for a forging at $0.1 \% \mathrm{Cu}, 0.7 \% \mathrm{Ni}$ and the nominal dose level in Table 1 is $17^{\circ} \mathrm{C}$ according to EWO, and this is similar to the increase for $0.1 \% \mathrm{Cu}$ indicated in Figure 10 for A508 Gr 4N. Solute fluctuations were observed in A508 Gr 4N steels under irradiation at test reactor flux levels to $18 \mathrm{mdpa}^{23}$. Radiation induced "precipitates" of $2-4 \mathrm{~nm}$ size with number density of about $6 \times 10^{23} / \mathrm{m}^{3}$ were reported in A508 $\mathrm{Gr} 4 \mathrm{~N}(0.08 \% \mathrm{Cu})$ at low flux to a dose of $68 \mathrm{mdpa}$, and the compositions were approximately 33 at $\% \mathrm{Ni}-15 \% \mathrm{Mn}-6 \% \mathrm{Cu}-5 \% \mathrm{Si}-41 \% \mathrm{Fe}^{23}$. Diffuse solute enriched clusters of similar density and size and the approximate composition 12 at $\% \mathrm{Ni}-11 \% \mathrm{Mn}-9 \% \mathrm{Cu}-$ $5 \%$ Si-balance $\mathrm{Fe}$ were reported in $\mathrm{A} 508 \mathrm{Gr} 2(0.12 \% \mathrm{Cu})$ irradiated at low flux to 85 $\mathrm{mdpa}^{23}$.

It is interesting to note that embrittlement may be slightly reduced with increasing carbon as shown in Figure 12, an effect not typically noted in the literature for other materials. Embrittlement apparently increased with increasing $\mathrm{Cr}$, but the effects were small, and not plotted.

\section{Conclusions}

- The increased nickel level in A508 Gr 4N produces significantly improved fracture toughness over A508 Gr 2.

- Radiation embrittlement data in A508 Gr 4N are very similar for the highest and lowest $\mathrm{Cu}$ levels tested, so that the embrittlement may be classified as "matrix" damage.

- The embrittlement of A508 Gr 4N is similar to that for A508 Gr 2, a conventional lower nickel steel, when tested at similar irradiation conditions and levels of contaminants.

- Literature data on 3Ni steels are bounded by data from A508 Gr 4N, except for two steels with either much higher $\mathrm{P}$ or much higher $\mathrm{Mn}$. 
- The irradiation temperature dependence and ratio of Charpy shift to radiation hardening for $\mathrm{A} 508 \mathrm{Gr} 4 \mathrm{~N}$ are very similar to the corresponding quantities for conventional low alloy steels.

- The increases of embrittlement due to $\mathrm{Cu}$ and $\mathrm{P}$ in $\mathrm{A} 508 \mathrm{Gr} 4 \mathrm{~N}$ are similar to low-alloy steels with lower nickel.

\section{Acknowledgements}

The authors wish to acknowledge T. J. Poskie for his contribution in assembling and cross-checking the database used for analysis.

\section{References}

1. L. E. Steele, J. R. Hawthorne, and R. A. Gray, Jr., "Neutron Irradiation Embrittlement of Several Higher Strength Steels", Effects of Radiation on Structural Metals, ASTM STP $426,1967, \mathrm{pp} 346-370$

2. R. J. Stofanak, T. J. Poskie, Y. Y. Li, and G. L. Wire, "Irradiation Damage Behavior of Low Alloy Steel Wrought and Weld Materials", Proceedings of Sixth Environmental Degradation of Materials in Nuclear Power Systems-Water Reactors , TMS, Warrendale, PA, 1993, page 757

3. R. J. Stofanak, Y. Y. Li, M. G. Burke, and K. Matuszyk, "Irradiation Embrittlement Behavior of High Strength Low Alloy Steels Containing about 3.3\% Nickel", Proceedings of the 10th Environmental Degradation of Materials in Nuclear Power SystemsWater Reactors , NACE, 2001

4. T. J. Williams and D. Ellis, " A Mechanistically-Based Model of Irradiation Damage in Low Alloy Steel Submerged Arc Welds", Effects of Radiation on Materials:20 ${ }^{\text {th }}$ International Symposium, ASTM STP 1405, 2001, pp 8-27

5. E. D. Eason, J. E. Wright, and G. R. Odette, "Improved Embrittlement Correlations for Reactor Pressure Vessel Steels, NUREG/CR-6551, MCS 970501, November, 1998

6. T. J. Williams, P. R. Burch, C. A. English, and P. H. N. de la cour Ray, "The Influence of Copper, Nickel, and Irradiation Temperature on the Irradiation Shift of Low Alloy Steels", Proceedings of the Second Environmental Degradation of Materials in Nuclear Power Systems-Water Reactors , ANS, TMS AIME, and NACE, 1985, pp 393399

7. L. E. Steele, "Neutron Irradiation Embrittlement of Reactor Pressure-Vessel Steels", Reprint from Atomic Energy Review ,Vol. VII., No 2, IAEA

8. L.E.Steele and C.Z.Serpan, "Neutron Embrittlement of PV Steels-A Brief Review", Analysis of Reactor Vessel Radiation Effects Surveillance Programs, ASTM 481, Chapter 2, 1970, pp 49-99

9. L. E. Steele and J. R. Hawthorne, "Neutron Embrittlement of Reactor Pressure Vessel Steels", NRL Report 5984, October 22, 1963

10. L. E. Steele and U. Potapovs, "Radiation Embrittlement of Reactor Vessel Steels and Suggestions for its Control", Nuclear Engineering and Design 8,1968, pp 58-70 
11. J. R. Hawthorne, "Irradiation Embrittlement", Treatise on Materials Science and Technology, Vol. 25, Academic Press, 1983, edited by C.L.Briant, S.K.Banerji

12. L. E. Steele, J. R. Hawthorne, and R. A. Gray, Jr., "Neutron Irradiation Embrittlement of Several Higher Strength Steels", Effects of Radiation on Structural Materials, ASTM STP 426, 1967, pp 346-370

13. J. R. Hawthorne, "Radiation Effects Information Generated On the ASTM Reference Correlation-Monitor Steels", ASTM DS 54, 1974

14. J. R. Hawthorne and L. E. Steele, "Metallurgical Variables as Possible Factors Controlling Irradiation Response of Structural Materials", Effects of Irradiation on Structural Metals, ASTM STP 426, 1967, pp 534-572

15. U. Potapovs and J. R. Hawthorne, "The Effect of Residual Elements on the Response of Selected Pressure-Vessel Steels and Weldments to Irradiation at $550^{\circ} \mathrm{F}^{\prime \prime}$, Nuclear Applications, Vol. 6, Jan 1969, pp 27-46

16. J. R. Hawthorne and E. Fortner, "Radiation and Temper Embrittlement Processes in Advanced Reactor Weld Metals", Journal of Engineering for Industry, August, 1972, Vol. 93, No 8, pp 807-814

17. J. R. Hawthorne, "Radiation Embrittlement Resistance of Advanced NiCrMo Steel Plates, Forgings, and Weldments", NRL Report 7573, Sept 13, 1973

18. J. R. Hawthorne, "Contributions of Selected Residual Elements to the RadiationEmbrittlement Sensitivity of Steel Forgings", NRL Report 7526, Jan 18, 1973

19. R. B. Jones and T. J. Williams, "The Dependence of Radiation Hardening and Embrittlement of Irradiation Temperature", Effects of Radiation on Materials:17th International Symposium, ASTM STP 1270, 1996, pp 569-90

20. G. R. Odette, "On the Dominant Mechanism of Irradiation Embrittlement of Reactor Pressure Vessel Steels", Scripta Metallurgica, Vol 17, 1983, pp 1183-1188

21. J. R. Hawthorne, "Trends in Charpy-V Shelf Energy Degradation and Yield Strength Increase of Neutron-Embrittled Pressure Vessel Steels", Nuclear Engineering and Design 11, 1970, pp 427-446

22. G.R.Odette, E.V.Mader, G.E.Lucas, W.J.Phythian, and C.A.English, "The Effect of Flux on the Radiation Hardening of Pressure Vessel Steels", Effects of Radiation on Materials:16th International Symposium, ASTM STP 1175, 1993, pp 373-392

23. M. G. Burke, R. J. Stofanak, J. M. Hyde, C. A. English, and W. A. Server "Characterization of Irradiation Damage in A508 Class2 and Class 4 Forging Steels", 10th Environmental Degradation of Materials in Nuclear Power Systems-Water Reactors, NACE, 2001 


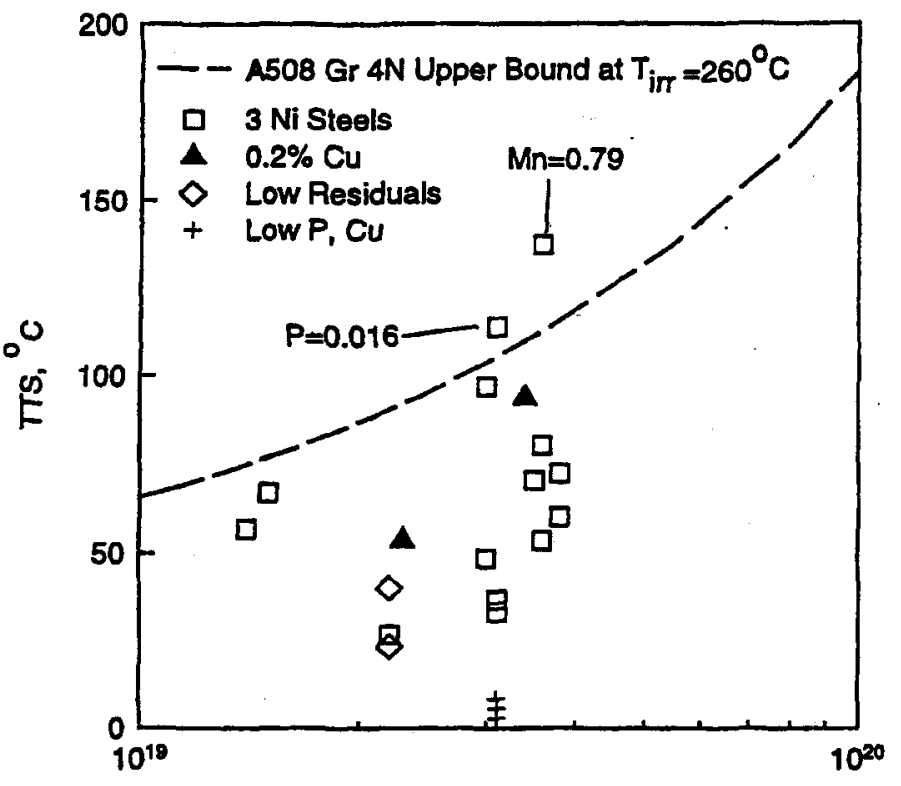

Fuence, $n / \mathrm{cm}^{2}, E>1 \mathrm{MeV}$ Figure 5. Literature Data on $3 \mathrm{Ni}$ Steels $\mathrm{T}_{\text {irr }}=254-288^{\circ} \mathrm{C}$, normalized to $260^{\circ} \mathrm{C}$

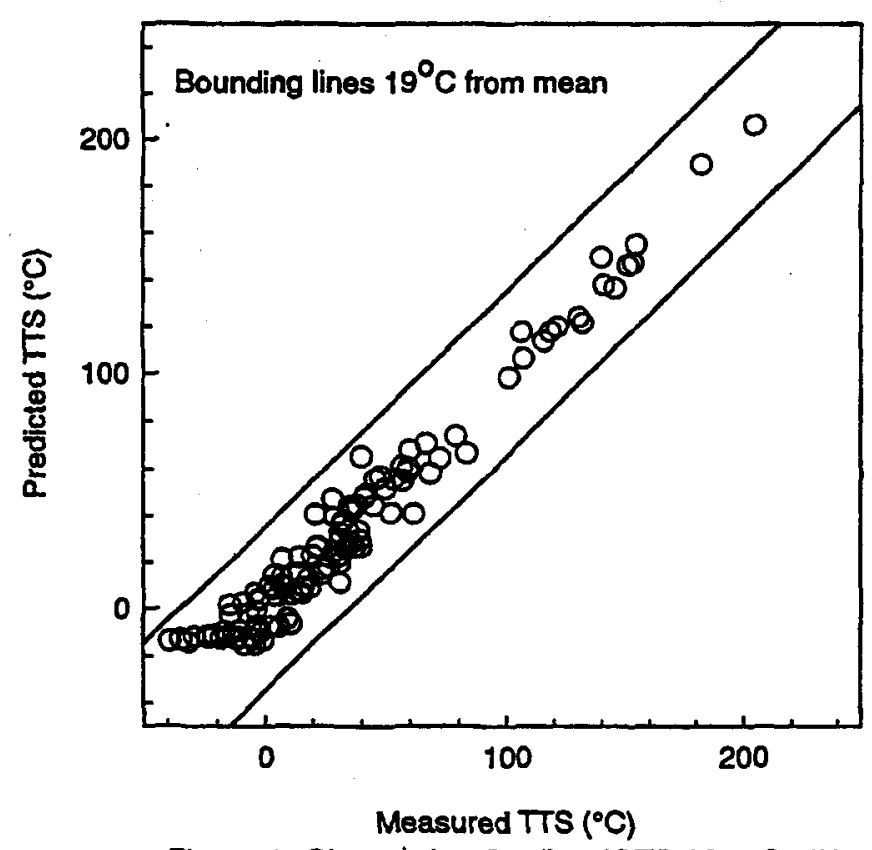

Figure 7. Observed vs Predicted TTS-A508 Gr 4N

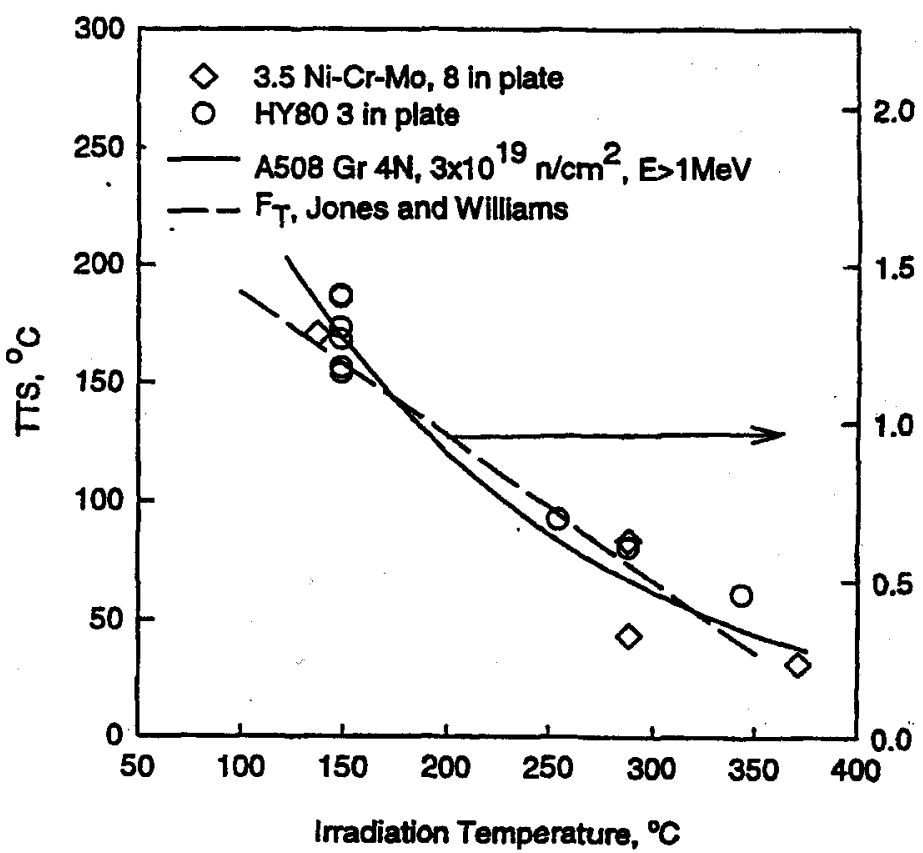

Figure 6. Embrittlement vs Irradiation Temperature Data normalized to $3 \times 10^{19} \mathrm{n} / \mathrm{cm}^{2}$, E>1MeV

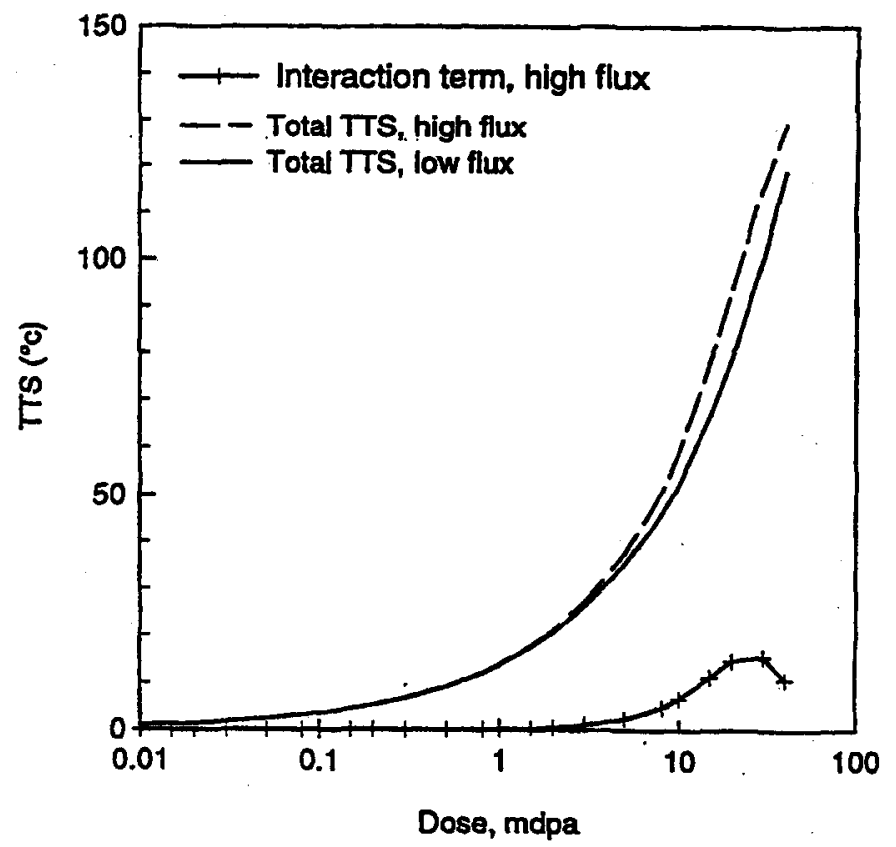

Figure 8. Predicted TTS at High and Low Flux Model for A508 Gr $4 \mathrm{~N}$ 


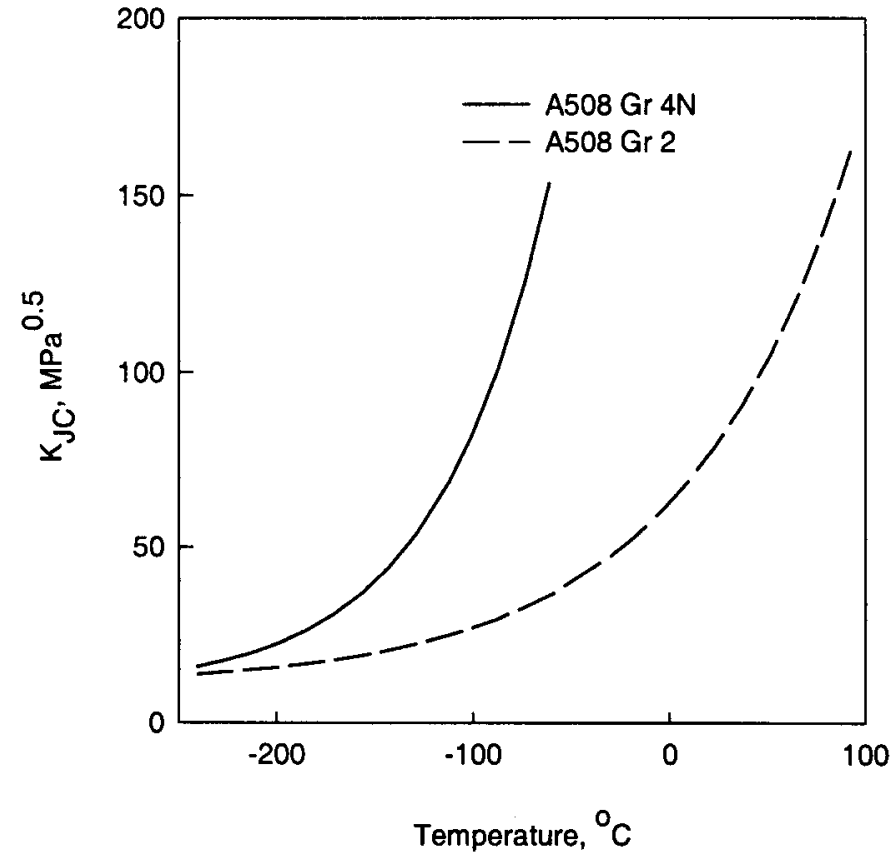

Figure 1. Lower Bound Fracture Toughness vs Test Temperature

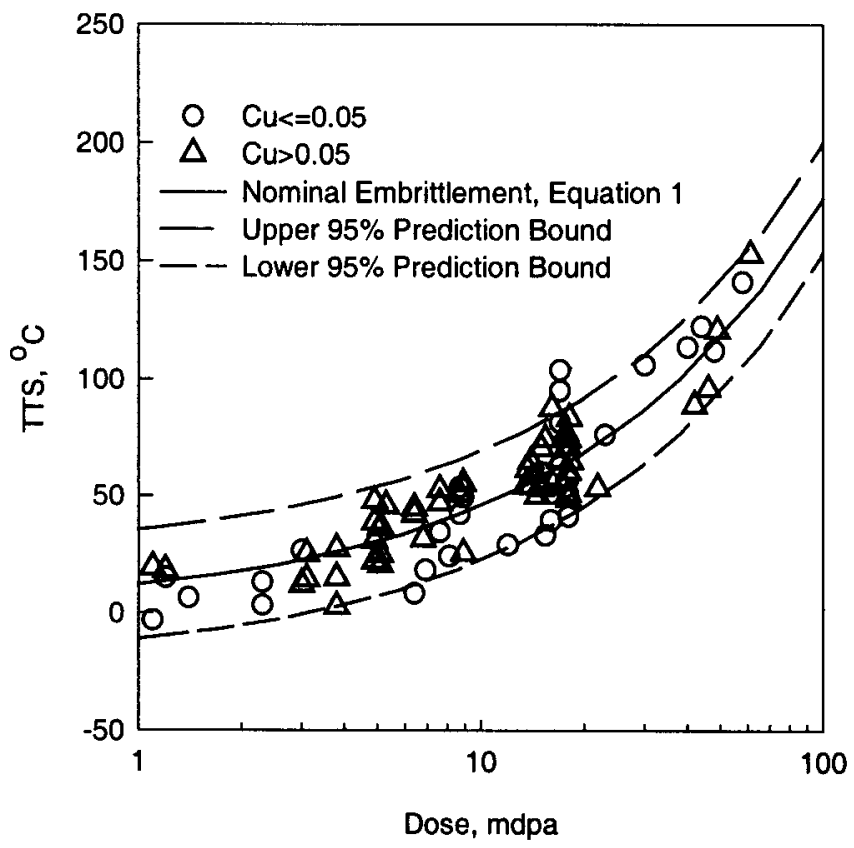

Figure 2. Embritlement of $\mathrm{A} 508 \mathrm{Gr} 4 \mathrm{~N}$ vs Dose

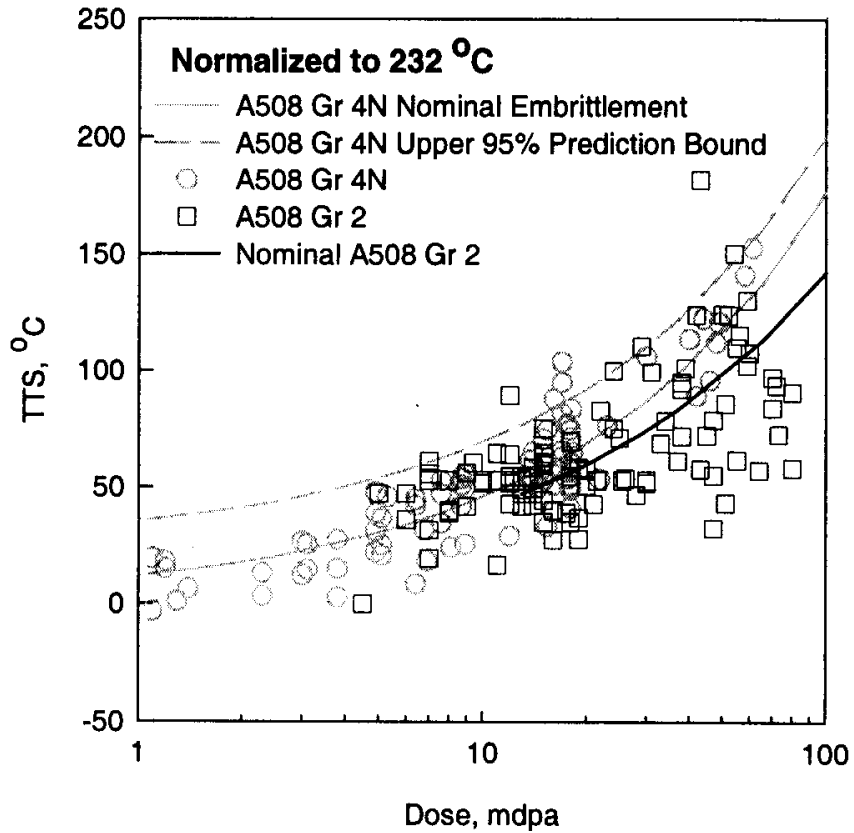

Figure 3. Embrittlement of A508 Gr 4N and A508 Gr 2

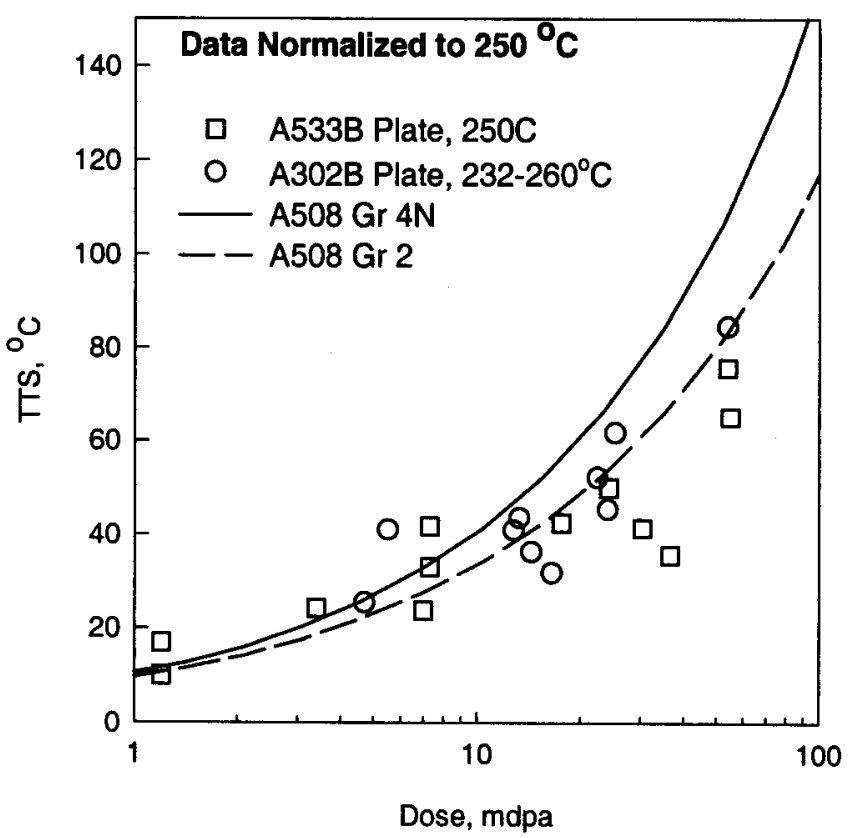

Figure 4. Embrittlement of Plate Steels, Cu<0.1\% 


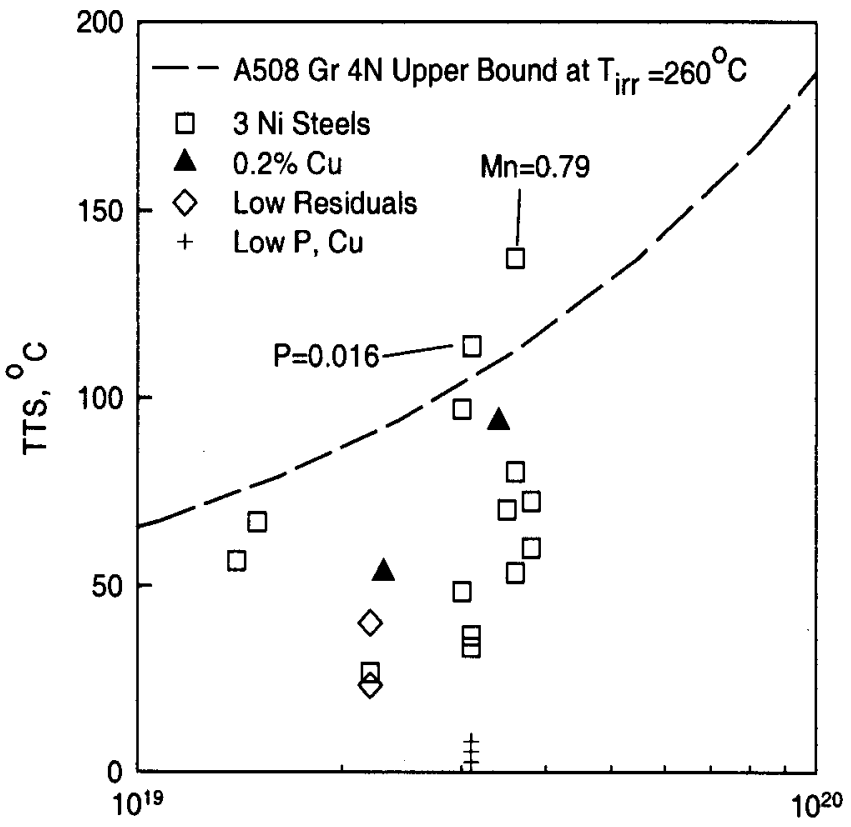

Fluence, $n / \mathrm{cm}^{2}, E>1 \mathrm{MeV}$

Figure 5. Literature Data on $3 \mathrm{Ni}$ Steels

$\mathrm{T}_{\text {irr }}=254-288^{\circ} \mathrm{C}$, normalized to $260^{\circ} \mathrm{C}$

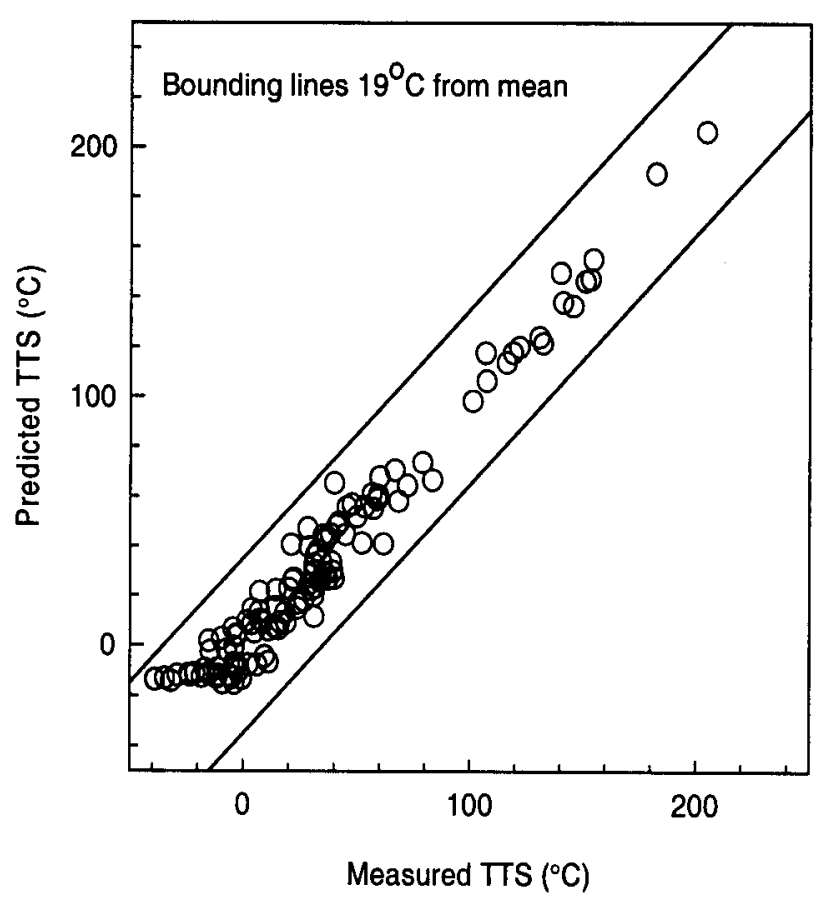

Figure 7. Observed vs Predicted TTS-A508 Gr 4N

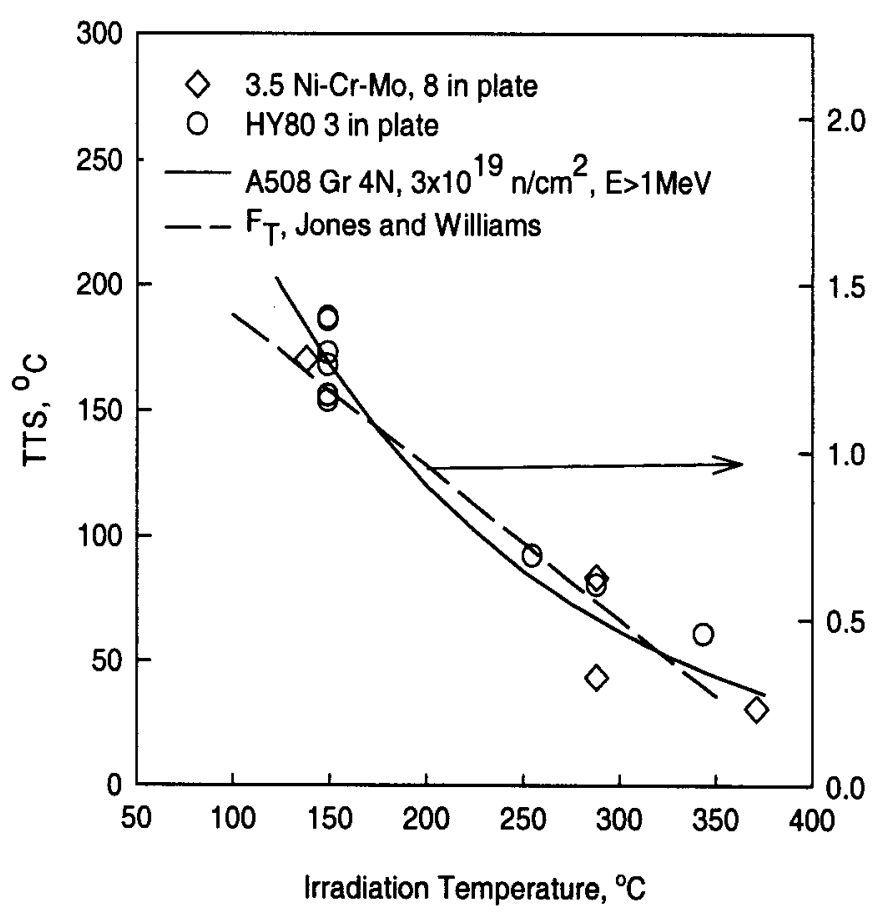

Figure 6. Embrittlement vs Irradiation Temperature Data normalized to $3 \times 10^{19} \mathrm{n} / \mathrm{cm}^{2}, E>1 \mathrm{MeV}$

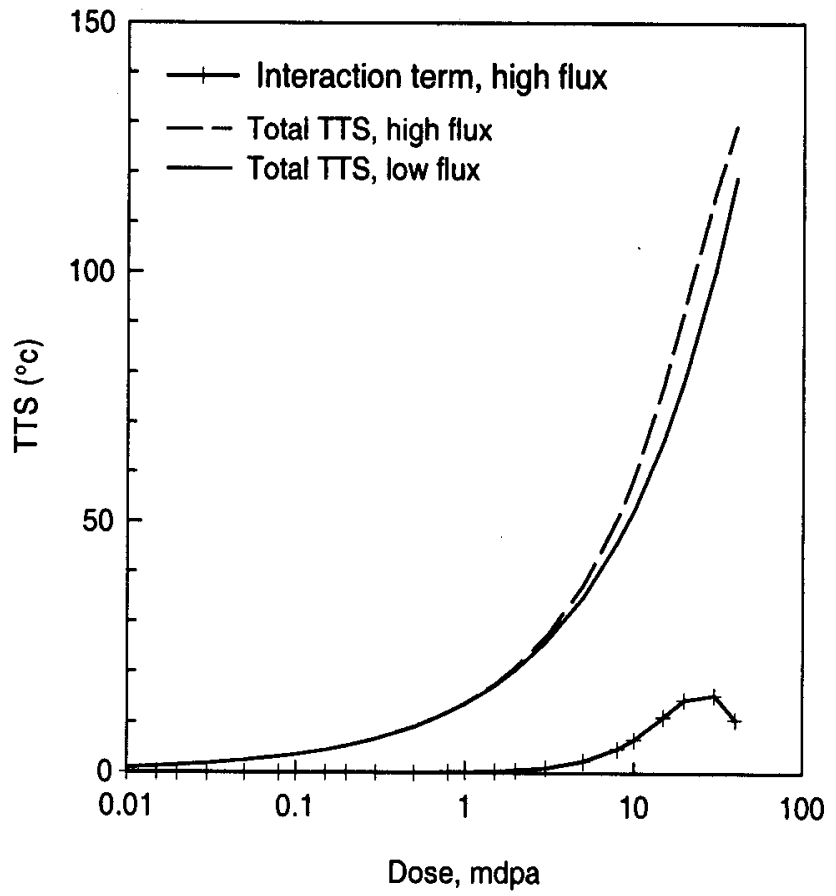

Figure 8. Predicted TTS at High and Low Flux Model for A508 Gr 4N 


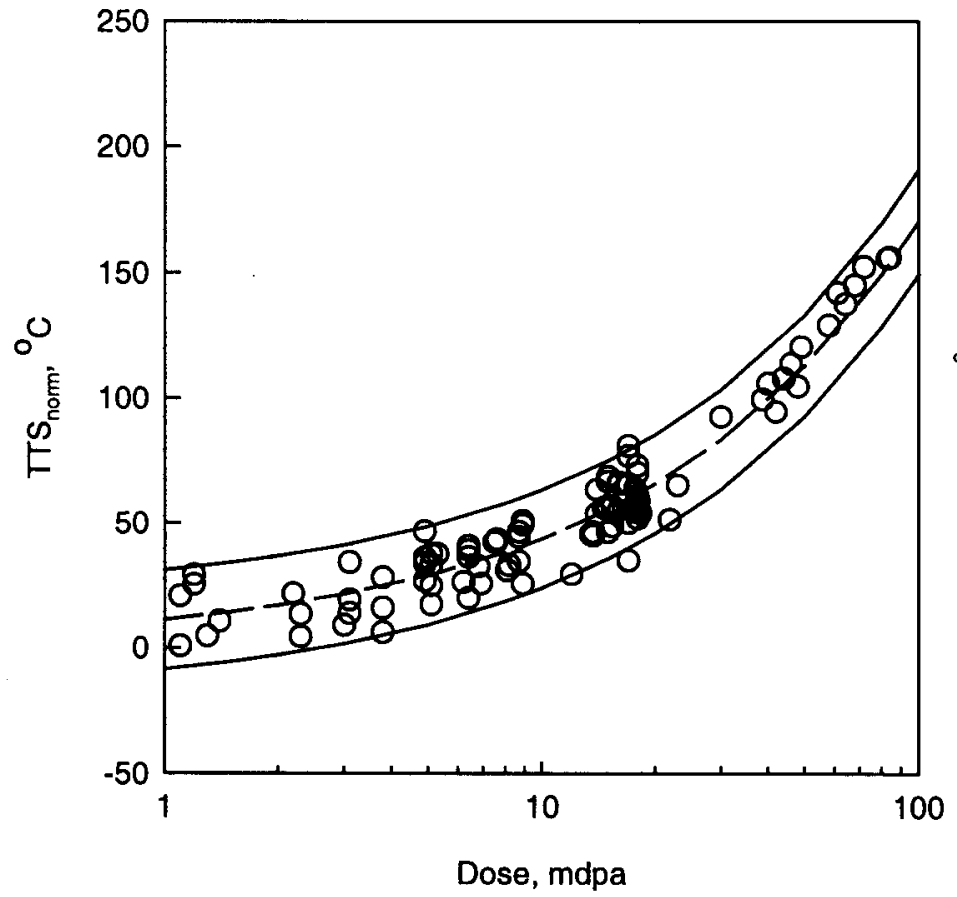

Figure 9. Normalized Embrittlement of A508 Gr $4 \mathrm{~N}$

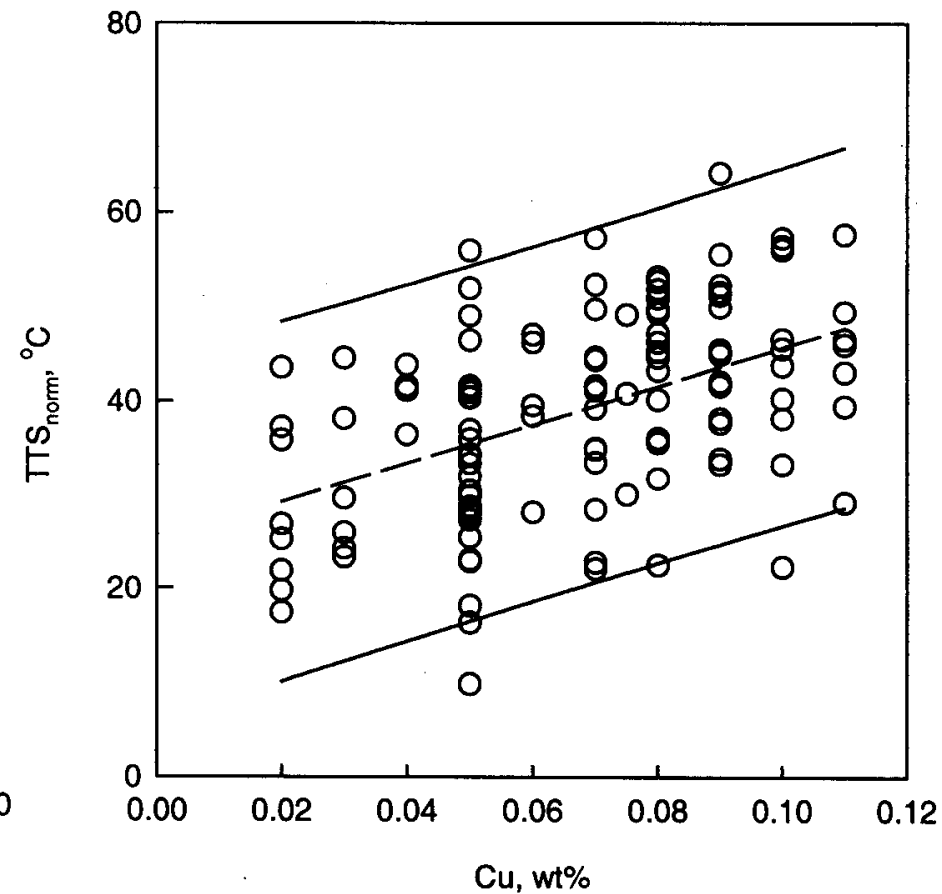

Figure 10. Effect of Cu on A508 Gr 4N Embrittlement

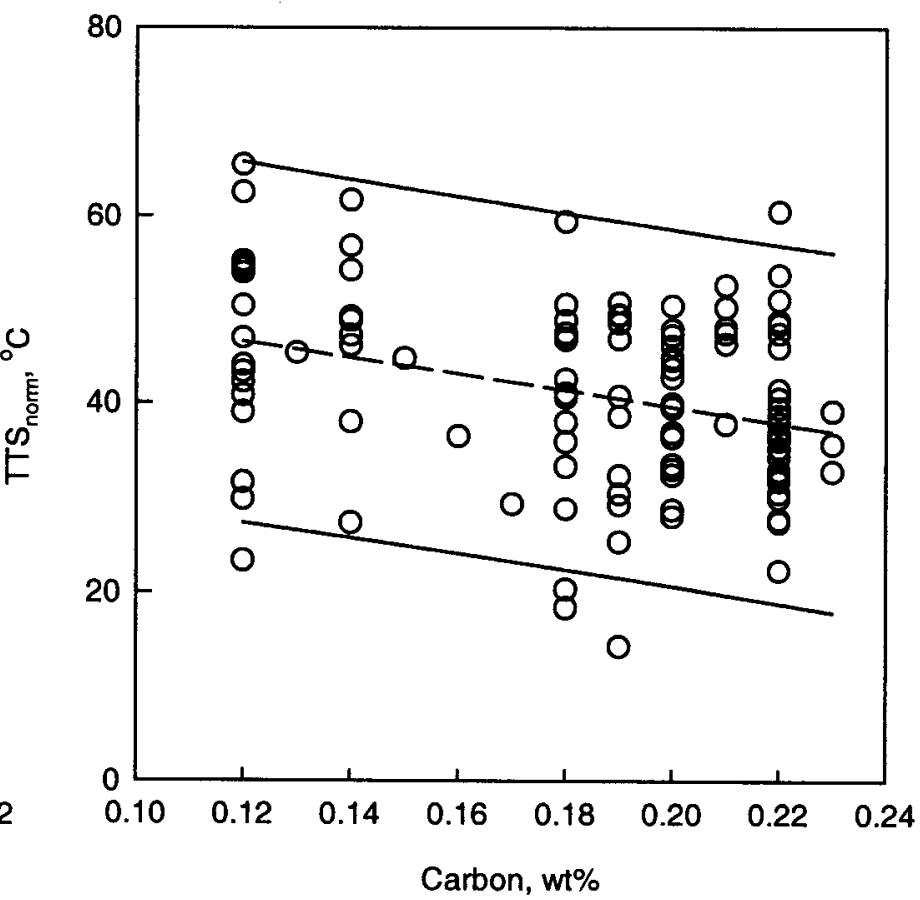

Figure 12. Effect of $C$ on $A 508$ Gr $4 \mathrm{~N}$ Embrittlement

Figure 11. Effect of $P$ on $A 508 \mathrm{Gr} 4 \mathrm{~N}$ Embrittlement 